\title{
Turf wars: competition between foundation and turf-forming species on temperate and tropical reefs and its role in regime shifts
}

\author{
John M. O'Brien*, Robert E. Scheibling \\ Department of Biology, Dalhousie University, Halifax, Nova Scotia B3H 4J1, Canada
}

\begin{abstract}
Shifts in competitive balance between key functional groups may drive regime shifts in tropical and temperate marine ecosystems. On shallow reefs, regime shifts increasingly involve changes from spatial dominance by foundation species (e.g. reefbuilding corals, canopy-forming algae) to dominance by turf-forming algae differing in structural complexity. To disentangle competitive interactions from other processes that may contribute to these shifts, we conducted a global meta-analysis of manipulative competition experiments between foundation and turf-forming species. Canopy-forming algae had consistently negative effects on abundance of turfforming algae, particularly on subtidal reefs, but with a tendency towards larger effects on delicate filamentous forms compared to articulated coralline and corticated/coarsely branching turf. Competitive effects of turf-forming algae on canopy species were limited to early life-history stages, and similarly varied between turf functional groups and between subtidal and intertidal reefs. Conversely, shorter filamentous turf assemblages typical of tropical reefs had no significant effect on settlement and survival of coral larvae. Interactions between turf-forming algae and established coral colonies were negative overall, but variable in magnitude. Mean effect sizes indicated that corals suppress turf abundance, but not vice versa. However, turf-forming algae significantly impacted coral growth and tissue mortality. We suggest reefs with extensive cover of foundation species are resistant to proliferation of turf algae, but competition will inhibit recovery of reefs following disturbances that enable turf algae to establish. Therefore, competitive effects of foundation and turf-forming species must be accounted for to effectively evaluate
\end{abstract}

${ }^{*}$ Corresponding author: jh876261@dal.ca

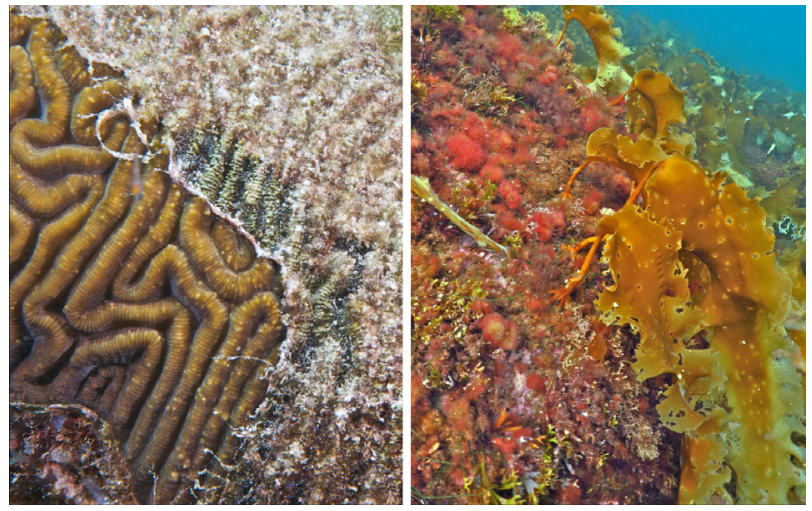

Foundation species such as reef-building corals and canopyforming brown algae face competition with low-lying turf algae on tropical and temperate reefs.

Photos: Alan Pinder \& Robert Scheibling

the stability of these undesirable regime shifts and recovery potential under alternative climate and management scenarios.

KEY WORDS: Competition - Turf algae - Coral · Canopy algae $\cdot$ Kelp $\cdot$ Meta-analysis

\section{INTRODUCTION}

There is growing recognition that diverse types of marine regime shifts, characterized by striking and abrupt changes in the structure of ecological communities (e.g. seagrass meadow collapse, kelp to sea urchin barren transitions; Möllmann et al. 2015), are

(C) The authors 2018. Open Access under Creative Commons by Attribution Licence. Use, distribution and reproduction are unrestricted. Authors and original publication must be credited. 
the outcome of one or more external drivers altering the internal dynamics of ecosystems (Connell et al. 2011, Conversi et al. 2015). These internal dynamics include interactions between trophic levels (e.g. predator-prey interactions) or within trophic levels (e.g. competition). Indeed, even before a contemporary theoretical framework surrounding these critical transitions developed (e.g. Scheffer et al. 2001), there was early recognition that classic Lotka-Volterra models of 2-species competition with unstable coexistence could describe dynamics consistent with regime shifts (Knowlton 1992). The drivers impacting these internal ecosystem dynamics are diverse (e.g. overfishing, nutrient input, ocean warming), frequently co-occur, and may be shared by multiple types of marine regime shifts (Rocha et al. 2015). The resulting changes involve key species or groups that structure the community, are often persistent over ecological time scales (Möllmann et al. 2015), and can lead to loss of ecosystem services (Rocha et al. 2015).

Such regime shifts on tropical and temperate reefs are increasingly reported to involve changes in spatial dominance from various foundation species to turf-forming algae (Filbee-Dexter \& Wernberg 2018). Foundation species (sensu Dayton 1972), such as reef-building corals in order Scleractinia and canopyforming algae in orders Laminariales and Fucales, have a large effect on community structure by providing framework and 3-dimensional spatial structure. In contrast, 'turf-forming' algae broadly describe algal assemblages that vary considerably in composition (single- or multi-species assemblages) and morphology (filamentous, corticated and coarsely branching, or articulated coralline algae), but are united by some consistent physical and functional characteristics. Generally, these assemblages form a pervasive, low-lying, and dense matrix of algal filaments, branches, and associated sediment (Connell et al. 2014). This is in contrast to the isolated individuals or patches of the component species that may occur on relatively pristine reefs.

On many degraded temperate rocky intertidal and subtidal reefs globally, turf-forming assemblages have replaced canopy-forming brown algae such as kelps and fucoids (Benedetti-Cecchi et al. 2001, Connell et al. 2008, Moy \& Christie 2012, Filbee-Dexter et al. 2016, Wernberg et al. 2016). In healthy tropical coral reef assemblages, turf algae also form a conspicuous component of the epilithic algal community (EAC) or epilithic algal matrix (EAM) and contribute considerably to the total primary productivity and trophic transfer, especially in lagoon, reef flat, and back-reef habitats (Hatcher \& Larkum 1983, Carpen- ter 1985, Klumpp \& McKinnon 1992, Wismer et al. 2009). As potential competitors, turf algae are in more frequent direct contact with coral colonies compared to other major functional groups of benthic reef organisms (Barott et al. 2012b, Wild et al. 2014, Jorissen et al. 2016) and rapidly colonize space following large-scale coral mortality (McClanahan et al. 2001, Adjeroud et al. 2009, Mellin et al. 2016). Algal turf forms the dominant component of benthic cover on many degraded coral reefs, rather than erect macroalgae (Haas et al. 2010, Vermeij et al. 2010, Barott et al. 2012b). However, the geographic extent and frequency of regime shifts from coral to turf algae are difficult to evaluate, as global analyses have focused on transitions to erect macroalgae, not turf algae (Bruno et al. 2009). Turf algae are structurally complex and provide habitat (Dijkstra et al. 2017), but on a fundamentally smaller scale compared to the habitat architecture, canopy structure, and standing biomass provided by the dominant foundation species on temperate and tropical reefs. Their proliferation therefore is considered a degraded reef state with respect to 3-dimensional structure and associated ecosystem services. Consequently, efforts to disentangle the processes behind the shifting nature of the interactions between these broad groups of organisms have intensified in both temperate and tropical systems.

Competition is thought to be a key ecological interaction between foundation species and turf-forming algae that contributes to or maintains regime shifts in reef ecosystems (McCook et al. 2001, Connell et al. 2013). Here we define competition as the negative effect one species or group has on the performance of another by consuming or interfering with access to resources (Keddy 2001). Despite structural and taxonomic disparities, foundation and turf-forming species may compete for nutrients and light. However, competition for space may be particularly intense, as it is a resource often in short supply on shallow benthic reefs and highly correlated with access to these other resources (Worm \& Karez 2002). This interaction can be largely hierarchical, with established corals and closed stands of canopy algae dominating over turf algae across a range of habitats (Johnson \& Mann 1988, McCook 2001). Nonetheless, when turf algae proliferate to pervade benthic habitat and form a thick and dense matrix, they can inhibit the establishment of macroalgal propagules (Gorman \& Connell 2009, Bellgrove et al. 2010) and coral larvae (Birrell et al. 2005). Consequently, turf algae are thought to become competitively superior under anthropogenically altered conditions that stimulate their 
growth (e.g. reduced herbivory, enriched nutrients; Gorgula \& Connell 2004, Barott et al. 2012b), thus reducing the resilience of foundation species to natural disturbances (Birrell et al. 2005, Connell et al. 2011) or facilitating direct overgrowth of established corals (Vermeij et al. 2010). Therefore, regime shifts toward spatial dominance by turf algae in response to reef degradation are thought to follow from a shift in the competitive balance between these key groups.

This emphasis on competition is sometimes based on observations that the relative abundances of foundation species and turf algae (Benedetti-Cecchi et al. 2001, Gorgula \& Connell 2004, Gorman et al. 2009, Wild et al. 2014), or the apparent outcome of interactions between them (Barott et al. 2012b), are reversed along gradients of anthropogenic influence (urbanization, nutrient input, fishing pressure). However, numerous other anthropogenic stressors lead to reef degradation (Rocha et al. 2015) and may directly influence nutrient enrichment and fishing (Ban et al. 2014) or combine in unexpected, non-additive ways (Strain et al. 2014). Many of these anthropogenic impacts are forms of stress or disturbance to corals and canopy algae. Here we define stress as external factors that limit growth and reproduction by diverting resources to prevent or repair damage (i.e. disruptive stress sensu Davison \& Pearson 1996). In contrast, disturbances are external factors (physical or biological) that cause partial or total removal of biomass (Grime 1977). Given that turf algae are often highly stress-tolerant and resistant or resilient to disturbance (Hay 1981, Airoldi 1998), forms of stress and disturbance that disproportionately affect foundation species may indirectly benefit turf algae. Trade-offs between competitive ability, stress tolerance, and resistance to disturbance form the basis of models of alternative evolutionary strategies and highlight that changes in patterns of dominance (i.e. numerical supremacy) are not necessarily an outcome of competitive interactions (Grime 1977, Keddy 2001). In their formative review, McCook et al. (2001) concluded that despite limited experimental evidence, coral-algal competition is likely a widespread process. However, a systematic evaluation of controlled experiments that separate competitive interactions between turf algae and corals or canopy algae from other processes is needed to weigh their contribution to such regime shifts on tropical and temperate reefs.

Here we provide the first quantitative synthesis, to our knowledge, of competitive interactions between foundation species and turf-forming algae across temperate and tropical marine ecosystems, in order to disentangle the role of competition in mediating regime shifts involving these groups. We conduct a meta-analysis of experiments measuring the effects of foundation species (canopy algae or corals) and turf algae on one another, quantify the magnitude and direction of these effects, and explore sources of variation (e.g. between foundation species lifehistory stages and turf algae functional groups). The definition of competition that we draw upon (see above) emphasizes both the effects and mechanisms of competition. Therefore, we also review and summarize the mechanisms of competition indicated in the literature to underlie these interactions. We then discuss how the results of this synthesis inform our understanding of the process by which regime shifts between foundation species and turf algae may be driven by shifts in the balance of competition, and address alternative mechanisms involving the disproportionate effects of stress and disturbance on these competing groups. We conclude with an outline for future research to explore the integrative effects of competition, stress, and disturbance in mediating regime shifts to turf algae and the stability of this generally undesirable ecosystem state.

\section{MATERIALS AND METHODS}

\section{Literature search and data extraction}

To assemble an exhaustive collection of studies measuring the competitive effects of canopy algae or corals and turf-forming algae on one another we conducted a systematic literature search of 'Title', 'Abstract', and 'Keyword' fields of the following databases: 'Web of science core collection' (1900-2017), 'Biological abstracts' (1926-2017), 'Aquatic sciences and fisheries abstracts' (1960-2017), and 'Dissertations and theses global' (1980-2017). We retrieved experimental studies in temperate rocky marine systems (intertidal or subtidal) using the following combinations of search terms or less restrictive subsets: (Canopy* OR Kelp* OR Laminariales OR Rockweed* OR Macroalga* OR Fucoid* OR Fucus OR Fucales OR Brown-alga* OR Habitat-form ${ }^{*}$ ) AND (Turf* OR Filament* OR Mat-form* OR 'Epilithic Alga"' OR 'EAC' OR 'EAM') AND (Compet* OR (Recruitment NEAR/5 Inhibit*) OR Canopy-Understor\$y OR 'Plant-Plant interaction*') AND (Experiment* OR Quantitative OR Empiric*). These search terms preclude studies on the effects of epiphytes. While some facultative algal epiphytes may decrease the performance of canopy algae (Worm \& Sommer 2000) and might also be present in turf assemblages (Kii- 
rikki 1996), we did not consider the effect of the epiphytic form to be a competitive effect of turf-forming algae per se. To retrieve equivalent studies from tropical reef systems, we conducted separate searches with the search term combinations: (Coral ${ }^{*}$ OR Scleractinia*) AND (Turf* OR Filament* OR Matform* OR 'Epilithic Alga*' OR 'EAC' OR 'EAM' OR 'Cyanobacter*') AND (Compet* OR Coral-Alga ${ }^{*}$ OR (Recruitment NEAR/5 Inhibit*)) AND (Experiment* OR Quantitative OR Empiric**). We also examined the reference lists of the relevant publications to identify additional relevant studies.

After screening titles and abstracts for obviously unrelated false positives, we further assessed the relevance of remaining publications identified from the literature search. We considered studies in the field, laboratory, or experimental mesocosms for inclusion in analyses provided they met the following 4 criteria (final yield $=69$ publications):

(1) Studies were manipulative experiments comparing the performance of the focal group or species (canopy algae or coral, turf-forming algae) between 2 treatments in which the hypothesized competing group or species (turf-forming algae, canopy algae or coral) was either absent or present. This included competitor removal (pulse or press), competitor addition, and transplantation type manipulations as well as manipulations of the competitor's effect (e.g. pretreatment of seawater with the competitor, interference with the mechanism of interaction). Studies lacking proper controls, that manipulated the competitor indirectly (e.g. through herbivore exclusion), or that quantitatively compared units where interactions were naturally occurring or absent were excluded.

(2) The 2 treatments were independently replicated.

(3) For temperate systems, the response of turf algae was measured between late spring to late summer to separate competitive effects from seasonal changes in algal growth and productivity.

(4) Information required to calculate effect sizes (means, sample sizes, and standard errors, standard deviations, or confidence intervals for both treatments) was reported or could be extracted from the article, or the raw data were made available by the authors or in a digital online repository.

To extract data for effect size calculations from the collection of 69 studies, we used graph-digitizing software, PlotDigitizer v. 2.6.2 (http://plotdigitizer. sourceforge.net/), whenever the information was not reported in the text or tables. We considered multiple measures of the performance of individual species and functional or morphological groups for analyses including abundance variables (\% cover, density, biomass), growth (size or change in size of whole/ parts of organisms), survival (\% survival, \% mortality, coral tissue damage/mortality), and response variables indicating the organism's physiological status or level of stress (e.g. effective quantum yield, density of coral symbiotic zooxanthellae, chl a content). If a study reported multiple response variables measuring the same phenomenon, we chose the variable most comparable with other studies in the analyses. For example, \% cover was preferred over biomass as a measure of turf algae abundance; for canopy algae recruitment, density was preferred over \% cover which was preferred over biomass; for coral physiological status, zooxanthellae density was preferred over effective quantum yield and chl $a$ content. For studies reporting results as a time series, we extracted data at the last time point within the seasonal constraints described above or, if recruitment was measured, during the recruitment period. For factorial experiments crossing competition orthogonally with other factors (e.g. temperature, sedimentation, herbivory, nutrient enrichment), we measured the effect of the competitor at the ambient level or in the absence of the additional factors. The aim of the analysis was to isolate, as much as possible, competitive interactions from the influence of external variables. This approach is a necessary first step towards determining how these interactions may be altered under changing external conditions.

Studies were further categorized by the life-history stage of canopy algae (microscopic recruit, i.e. embryo, zygote, microscopic germling; macroscopic recruit; adult) or coral (recruit, i.e. larva to primary polyp; established, i.e. juvenile to adult) and functional group of turf-forming algae (filamentous; corticated/coarsely branching; articulated coralline). This functional group designation of turf algae captures a gradient of increasing thallus longevity and decreasing mass-specific productivity (Steneck \& Dethier 1994). We included benthic cyanobacteria (e.g. Lyngbya spp.) in the filamentous category because they may be mixed with filamentous algae in tropical turf assemblages (McCook 2001) and appear similar on a macroscopic and functional level. Temperate reef studies were also grouped into intertidal or subtidal assemblages.

\section{Effect sizes and data analysis}

We measured the effect of the competitor for each study as the bias-corrected standardized mean dif- 
ference, Hedges' $g$ (Hedges \& Olkin 1985), between the competitor present and competitor absent treatments as follows:

$$
\text { Hedges' } g=\frac{\bar{Y}_{\text {competitor }}-\bar{Y}_{\text {no competitor }}}{S_{\text {Pooled }}}(J)
$$

where $\bar{Y}_{\text {competitor }}$ and $\bar{Y}_{\text {no competitor }}$ are the mean responses in the competitor present and absent treatments, respectively, $S_{\text {Pooled }}$ is the pooled standard deviation of the 2 groups, and $J$ is a correction factor based on sample sizes. A negative value of $g$ indicates a reduction in performance of the focal group in response to the competitor. For publications that reported results for multiple independent experiments or replicated experiments at multiple sites separated by $>1 \mathrm{~km}$, at different times of the year, in different years, or with different species/functional groups, we calculated effect sizes for each of these experiments separately. These were treated as independent studies. When multiple response variables measuring different phenomena were reported for replicates within the same experiment (e.g. growth and survival), effect sizes were measured for each response variable, but treated in separate analyses.

We used random effects or mixed effects models to calculate overall effect sizes across studies for each combination of response variable, competitors (canopy algae, coral, turf-forming algae), life-history stage of canopy algae or coral, and functional group of turf for which there was sufficient data. The random effects model attributes variation between individual effect estimates to within-study variance (sampling error) and between-study variance (variation in true effect sizes; Borenstein et al. 2009). The mean effect size is calculated by weighting studyspecific estimates by the inverse of their variance, which includes a common between-study variance. We used the DerSimonian \& Laird (1986) approximation to estimate the between-study variance. Mixed effects models allow for systematic comparisons of subgroups of the data (moderator analysis) to be made by testing the significance of the heterogeneity between groups $\left(Q_{M}\right)$, and assume fixed differences in the true mean effect size between subgroups, but that true effect sizes of studies within a subgroup vary randomly around the subgroup mean (Borenstein et al. 2009). As with random effects models, study-specific estimates in mixed models are weighted by the inverse of their variance, which includes a common between-study variance. We used mixed effects models to test the null hypotheses of no fixed difference in effect of canopy algae on the abundance of turf algae between (1) functional groups of turf and (2) intertidal and subtidal reefs. Similarly, we tested the null hypotheses of no fixed difference in effect of turf algae on the abundance of canopy algae recruits between (1) functional groups of turf, (2) microscopic and macroscopic recruits, and (3) intertidal and subtidal reefs.

A subset of canopy manipulation experiments measured the response of multiple functional groups of turf algae within the same plots. Treating these measures as independent will over- or underestimate the precision of the effect size estimates if they are positively or negatively correlated, respectively (Borenstein et al. 2009). Because the non-independence issue was relevant to a minority of canopy manipulation experiments $(27 \%)$, and those for which we had raw data indicated that correlations among functional groups were weak $(r<0.3)$ and typically negative, we opted to treat measures of different functional groups within the same plot as independent in the analyses. Our calculations ignoring correlations likely overestimate variances around these mean effect sizes and our inferences based on them are therefore more conservative.

To evaluate evidence of publication bias we used funnel plots to aid visual interpretation. A scarcity of studies with small sample sizes (large SE) and nonsignificant outcomes results in a linear relationship between sample size and effect size and an asymmetric funnel plot. We tested for asymmetry of funnel plots using Kendall's rank correlation between standardized effect sizes and standard errors $(\alpha=0.10)$. We also calculated Rosenthal's fail-safe number for each overall effect size or subgroup mean as a sensitivity analysis; this is an estimate of the number of unpublished studies with null effects that, if included (unweighted) among the studies located by the metaanalyst, would be required to reduce the significance below $\alpha=0.05$ (Rosenthal 1979). For comparison, we also calculated Rosenberg's fail-safe number, which is based on weighted meta-analysis and estimates the weight of a single additional study, relative to the average of those included in the model, with a null effect necessary to reduce the significance below $\alpha=$ 0.05 (Rosenberg 2005). These computations were made with the fail-safe number calculator available online (Rosenberg 2005). All other analyses were conducted in $\mathrm{R}$ version 3.1.3 (R Core Team 2015) using the metafor package (Viechtbauer 2010).

There was evidence of funnel plot asymmetry indicative of publication bias for the abundance of turf algae competing with canopy algae (see Fig. S1A and Table S1 in the Supplement at www.int-res.com/ articles/suppl/m590p001_supp.pdf) or coral (Fig. S1B, 
Table S1), and coral growth (Fig. S1F, Table S1), but not the other variables (Fig. S1D-E,G,H, Table S1). It should be noted that some funnel plots were based on a relatively small number of studies, and asymmetry may emerge by chance (Jennions et al. 2013). Of those variables showing funnel plot asymmetry, Rosenthal's fail-safe numbers indicated the results were relatively robust to overestimates of the true effect size (Table S1). Rosenberg's fail-safe numbers indicated that results of all models would be more sensitive to publication bias in comparison to Rosenthal's fail-safe (Table S1).

\section{Mechanisms of competition}

In addition to the systematic search for manipulative experiments measuring the competitive effects of canopy algae or corals and turf-forming algae on one another, we also surveyed the extracted literature and their references for studies reporting or evaluating the mechanisms by which these groups suppress the performance of their competitors.

\section{RESULTS AND DISCUSSION}

\section{Description of datasets}

From the 69 publications reporting results of manipulative experiments that met our inclusion criteria (Appendix S1 in the Supplement), we extracted 193 effect sizes (Hedges' $g$ ) measuring the impact of foundation species on the performance of turf-forming algae or vice versa. These involved a variety of different species and genera (Table S2 in the Supplement). The majority $(73 \%)$ of these effect sizes came from experiments in temperate rocky reef systems and the number of publications and study-specific effect sizes contributing to each overall effect size calculation varied considerably (Table S3 in the Supplement). Both tropical and temperate studies were distributed broadly across the globe, but with some regional biases (Fig. S2 in the Supplement, Table S2). Tropical studies were concentrated within the Great Barrier Reef (18) and Caribbean (17), with the remainder scattered across the Philippine Sea (4), North (5) and South Pacific (4), South Atlantic (1), and Florida Keys (3). Temperate studies were conducted on the west (49) and east (14) coasts of North America, in the NE Atlantic (8), Baltic Sea (10) and Mediterranean Sea (20), around Australia and New Zealand (37), and in the Korea Strait (3), but with noticeable gaps on the west coasts of South America and Africa. The year of publication of studies included in the analyses ranged from 1981 to 2017 with an increasing frequency through time (Fig. S3 in the Supplement). There was a considerable increase in the number of publications beginning in the late 1990s and early 2000s, concurrent with the first publications of experiments on tropical reefs (Fig. S3). The duration (mean \pm SD) of experiments ranged from $5 \pm 2 \mathrm{~d}$ (median $=5 \mathrm{~d}$ ) for studies on the effects of filamentous turfs on the survival of coral recruits to $706 \pm 763 \mathrm{~d}$ (median $=485 \mathrm{~d}$ ) for studies on the effects of canopy algae on the abundance of articulated coralline turfs (Table S3). The average study duration rarely spanned multiple years (Table S3).

\section{Competitive effects on temperate reefs}

Canopy algae had significant negative effects on all 3 functional groups of turf-forming algae, but with a trend toward a greater negative effect on more delicate filamentous turf algae compared to the articulated coralline and corticated/coarsely branching groups (Fig. 1A). However, the mixed effect model indicated turf functional group did not explain significant variation in effect of canopy algae $\left(Q_{M}=2.80, \mathrm{p}=\right.$ 0.246). Currents and water flow are reduced within canopies of brown algae (Jackson \& Winant 1983, Irving \& Connell 2006b), which could inhibit turf algae by affecting recruitment or the rate of nutrient uptake. However, there is little experimental evidence to support a strong effect of reduced water flow per se on algal assemblages in the understorey (Wernberg et al. 2005, Russell 2007). More commonly, canopies of brown algae suppress the growth of turf-forming algae in the understorey by reducing the availability of light (Kim 2002, Connell 2005, Wernberg et al. 2005, Russell 2007) or through the abrading, sweeping motion ('whiplash') of algal fronds (Irving \& Connell 2006a,b, Russell 2007) with water movement (Fig. 2A,B). The more robust morphology and increased shade tolerance (Häder et al. 2003, Toohey et al. 2004, Irving \& Connell 2006a) of articulated coralline and corticated/coarsely branching turf algae may impart greater resistance to the effects of shading and abrasion/whiplash by canopy algae. Alternatively, the trend towards smaller effects on these groups may reflect a facilitating effect of brown algal canopies in some circumstances (Figs. S4 \& S5 in the Supplement). In contrast to fugitive species, so called obligate understorey species are much reduced in abundance when the ameliorating effect of the 


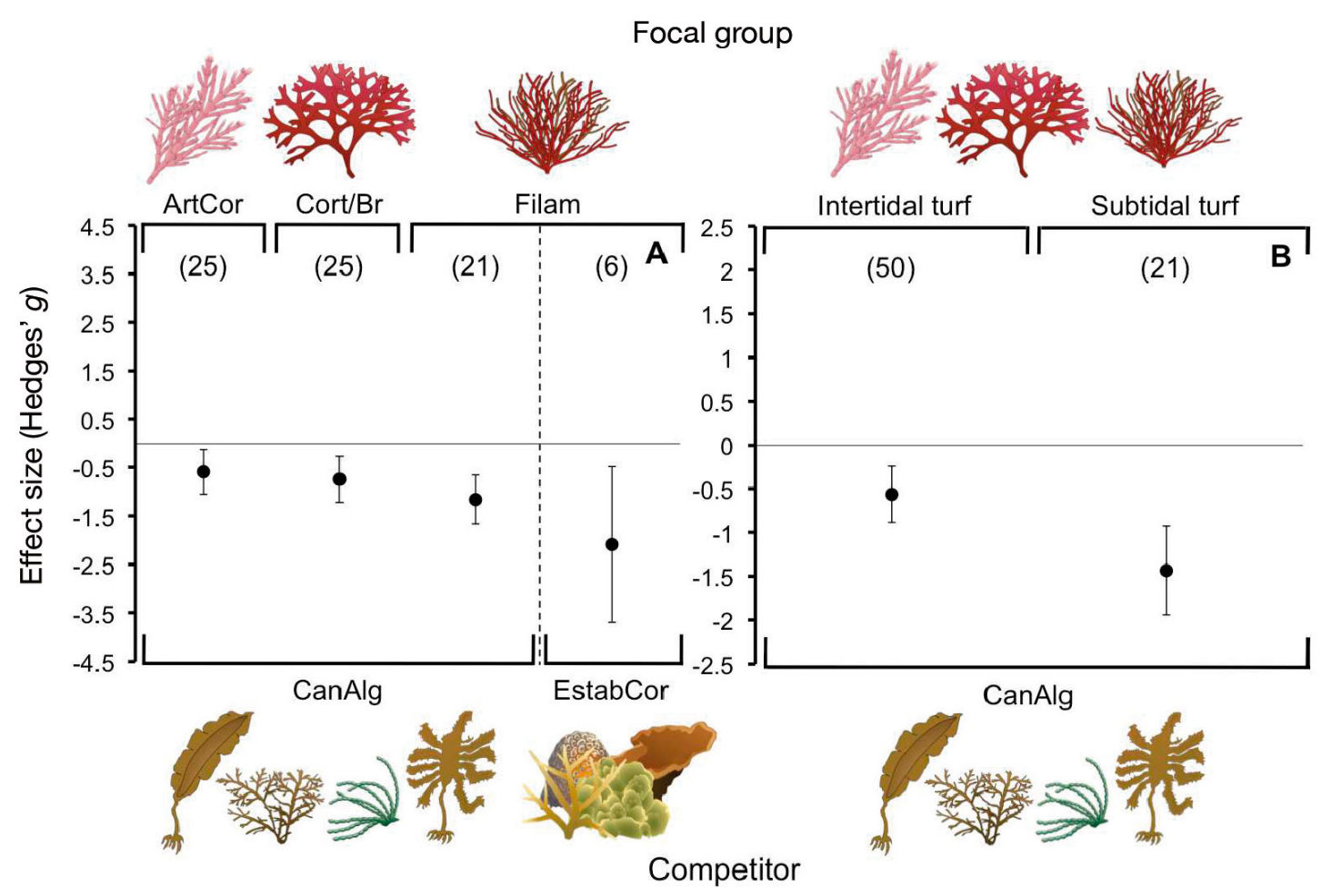

Fig. 1. Competitive effects (standardized mean difference) of canopy algae and established corals (Competitors: CanAlg, EstabCor) on abundance of turf-forming algae (Focal groups). Effects are grouped by turf algae in (A) 3 functional groups: articulated coralline (ArtCor), corticated/coarsely branching (Cort/Br), and filamentous algae (Filam); and (B) intertidal and subtidal assemblages. Data are mean effect sizes calculated from mixed or random effects models and $95 \%$ confidence intervals. Numbers of study-specific effect sizes contributing to each overall effect size are shown above the data points. Image credits: Tracey Saxby (Chondrus, Hormosira, Cystoseira, Acropora, plate and encrusting coral), Joanna Woerner (Porites lobata), and Dieter Tracey (filamentous algae). Integration and Application Network, University of Maryland Center for Environmental Science (ian.umces.edu/imagelibrary/)


Fig. 2. Mechanisms of competition between canopy algae and turf-forming algae. Canopy algae suppress turf algae through (A) shading and (B) abrasion/ whiplash. Turf algae (C) inhibit early life-history stages of canopy algae by (1) forming a settlement barrier or (2) increasing postsettlement mortality via sediment smothering, shading, overgrowth, or allelopathic exudates; and (D) cause post-recruitment mortality of macroscopic recruits via dislodgement/sloughing. Image credit: Dieter Tracey (filamentous algae). Integration and Application Network, University of Maryland Center for Environmental Science (ian.umces.edu/ imagelibrary/) 
canopy to temperature, high light, and desiccation stress is removed (Dayton 1975, Cervin et al. 2005). Consequently, compared to subtidal reefs, the mean effect of canopy algae on turf algae was significantly less negative on intertidal reefs where more intense physical stress would make the ameliorating effect of the canopy more beneficial (Fig. $1 B_{;} Q_{M}=8.07, \mathrm{p}<$ 0.01).

While adult canopy algae directly suppress turfforming algae, reciprocal effects of turf-forming algae are largely limited to the early life-history stages of canopy algae. We found only 2 publications investigating effects of turf-forming algae on adults. These studies reported either neutral (BenedettiCecchi et al. 1996) or facilitating effects (Barner et al. 2016). Turf-forming algae limited recruitment of kelps and fucoids, but the mean effects also varied between functional groups of turf (Fig. 3A). Turf functional group explained significant heterogeneity in effect sizes $\left(Q_{M}=8.45, \mathrm{p}=0.015\right)$. Corticated/ coarsely branching and filamentous turf algae had significant negative effects on the abundance of recruits (Fig. 3A). In contrast, the negative effect of articulated coralline algae on recruit abundance was small and non-significant $($ mean $=-0.34,95 \% \mathrm{CI}=$ -0.99 to 0.31 ; Fig. 3A). While most individual studies reported negative effects, others reported positive effects of articulated coralline turfs on the recruitment of kelps and fucoids; all of these were intertidal studies (Fig. S6 in the Supplement). Pooled across all functional groups of turf algae, the overall effect size for studies on intertidal reefs did not differ from zero and was significantly different from studies on subtidal reefs (Fig. 3B; $Q_{M}=16.9, \mathrm{p}<0.001$ ). The greater frequency of positive interactions in intertidal compared to subtidal assemblages is consistent with the stress-gradient hypothesis (Bertness \& Callaway 1994), suggesting that the ameliorating effects of turf algae on physical extremes in temperature (Brawley \& Johnson 1991) and water motion (Vadas et al. 1990) experienced by intertidal algal propagules outweigh potential negative effects. Positive effects on propagules and recruits also may arise if turf algae limit the movement or activity of grazers (Harris et al. 1984, Benedetti-Cecchi \& Cinelli 1992). The mean effect of turf algae on microscopic recruits also was twice as large compared to macroscopic recruits (Fig. 3C), suggesting that the most intense competition from turf occurs at the earliest life-history stages. However, life-history stage was marginally non-significant when included as a moderator in a mixed effect model $\left(Q_{M}=3.62, \mathrm{p}=0.057\right)$.

Variation between functional groups of turf algae in their effects on recruitment of canopy algae, and a

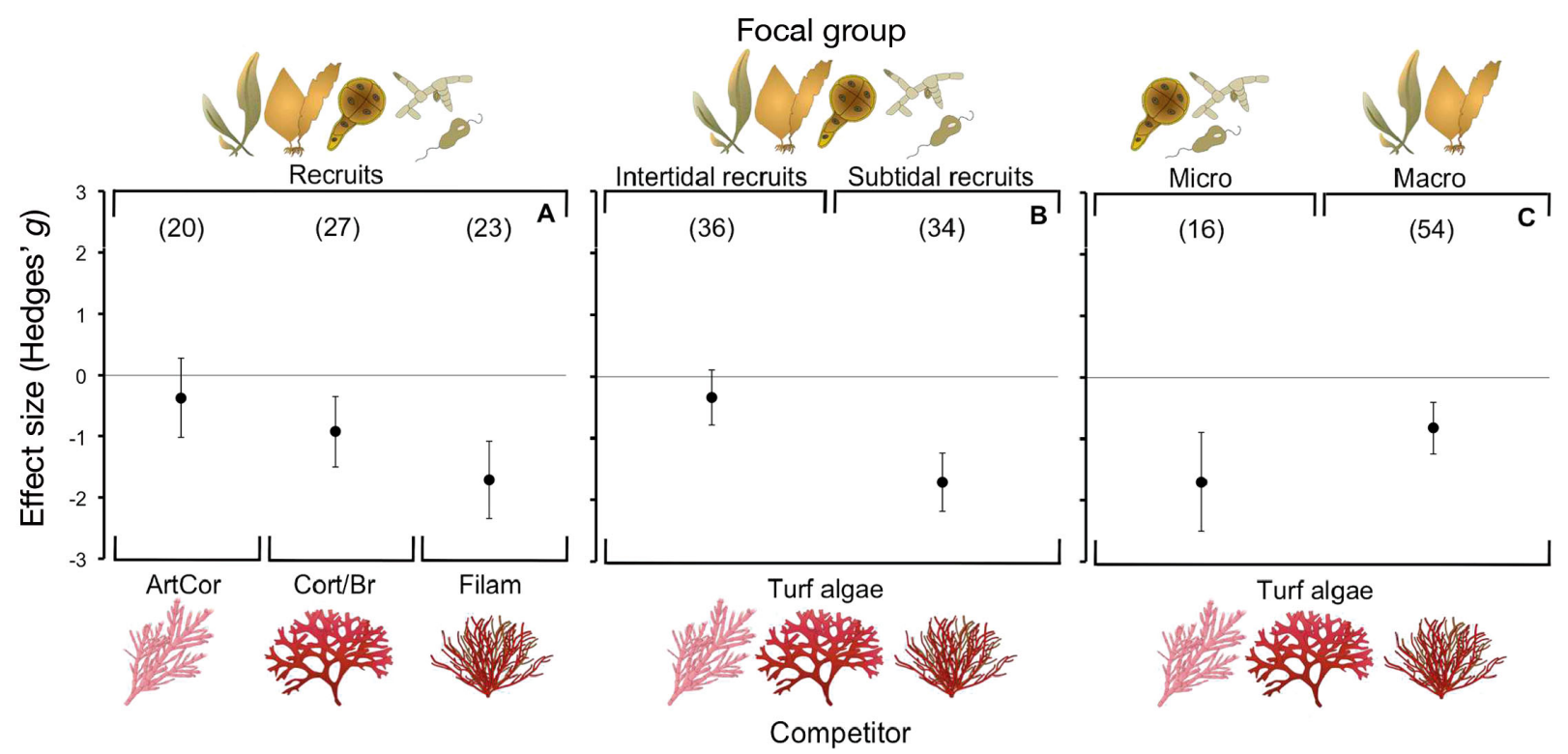

Fig. 3. Competitive effects (standardized mean difference) of turf-forming algae (Competitors) on abundance of early lifehistory stages of canopy algae (Focal groups). Effects are grouped by (A) turf functional group (see Fig. 1), (B) intertidal and subtidal assemblages, and (C) microscopic (Micro: zygotes, embryos, germlings) and macroscopic (Macro) recruits. Data are mean effect sizes calculated from mixed effects models and $95 \%$ confidence intervals. Numbers of study-specific effect sizes contributing to each overall effect size are shown above the data points. Image credits: Tracey Saxby (Chondrus), and Dieter Tracey (filamentous algae). Integration and Application Network, University of Maryland Center for Environmental Science (ian.umces.edu/imagelibrary/) 
larger effect on microscopic recruits, might also reflect variation in the mechanisms of competition. The dense matrix of algal branches in turf assemblages forms a settlement barrier to propagules of canopy algae (Fig. 2C; Isæus et al. 2004, Råberg et al. 2005, Bellgrove et al. 2010) that is exacerbated by associated sediments (Alestra et al. 2014). Inorganic sediments prevent attachment of fucoid zygotes and kelp spores (Devinny \& Volse 1978, Schiel et al. 2006, Deiman et al. 2012) or smother attached microscopic stages (Devinny \& Volse 1978, Isæus et al. 2004). Fine-branching filamentous forms may create a more tightly woven matrix of algal branches or more effectively trap and stabilize sediments than coarsely branching forms. In addition to smothering by sediments, turf algae can directly cause post-settlement mortality of recruits (Fig. 2C). The effects of corticated turf algae and fast-growing filamentous forms via overgrowth (Steen 2004) and shading (Worm \& Chapman 1998, Steen 2004) may be particularly large on microscopic recruits, but decrease once canopy algae reach a size refuge. Limited evidence suggests some filamentous forms also release exudates that decrease settlement success and increase post-settlement mortality (Råberg et al. 2005, Svensson et al. 2013), but similar allelopathic effects for articulated coralline algae are equivocal (Bellgrove et al. 2010, Alestra et al. 2014). Post-recruitment mortality can also result from dislodgement of macroscopic recruits attached to certain forms of turf algae (K. Burek unpubl.; Fig. 2D). While filamentous and corticated/coarsely branching turf forms greatly reduce the attachment strength of kelp (K. Burek unpubl.), articulated coralline algae may strengthen attachment (Milligan \& DeWreede 2000).

\section{Competitive effects on tropical reefs}

In contrast to temperate reefs, filamentous turf algae on tropical reefs had no significant effect on the survival of settling coral larvae and primary polyps (Fig. 4). This may reflect differences in the structure of turf assemblages, which tend to be composed largely of short ( $\mathrm{mm}$ to $\mathrm{cm}$ ), cropped filamentous forms on tropical reefs (e.g. Wismer et al. 2009, Harris et al. 2015), but reach greater heights ( $\mathrm{cm}$ to $10 \mathrm{~s}$ of $\mathrm{cm}$ ) on temperate reefs (e.g. Berger et al. 2003, Bellgrove et al. 2010). The greater size of coral larvae compared to kelp spores and motility compared to fucoid zygotes could also explain this difference between community types. However, the average duration of the included experiments was relatively short $(5 \mathrm{~d})$, and larger effects of turf algae on coral recruits may emerge over time. Variation between tropical turf assemblages in their effect on coral settlement and recruitment (Fig. S7 in the Supplement) also may be related to turf height, density, and composition (Birrell et al. 2005). Particular assemblages of tropical turf algae inhibit coral recruitment by forming a barrier to settlement (Fig. 5A; Birrell et al. 2005) or by overgrowing small settlers (Fig. 5B; Birkeland 1977, Bak \& Engel 1979). Chemical cues from turf algae also may deter coral larvae from settling, as has been shown for other tropical macroalgae (Dixson et al. 2014).

Our results not only suggest that filamentous turfs generally do not limit the establishment of corals, but also that previously established corals have a strong

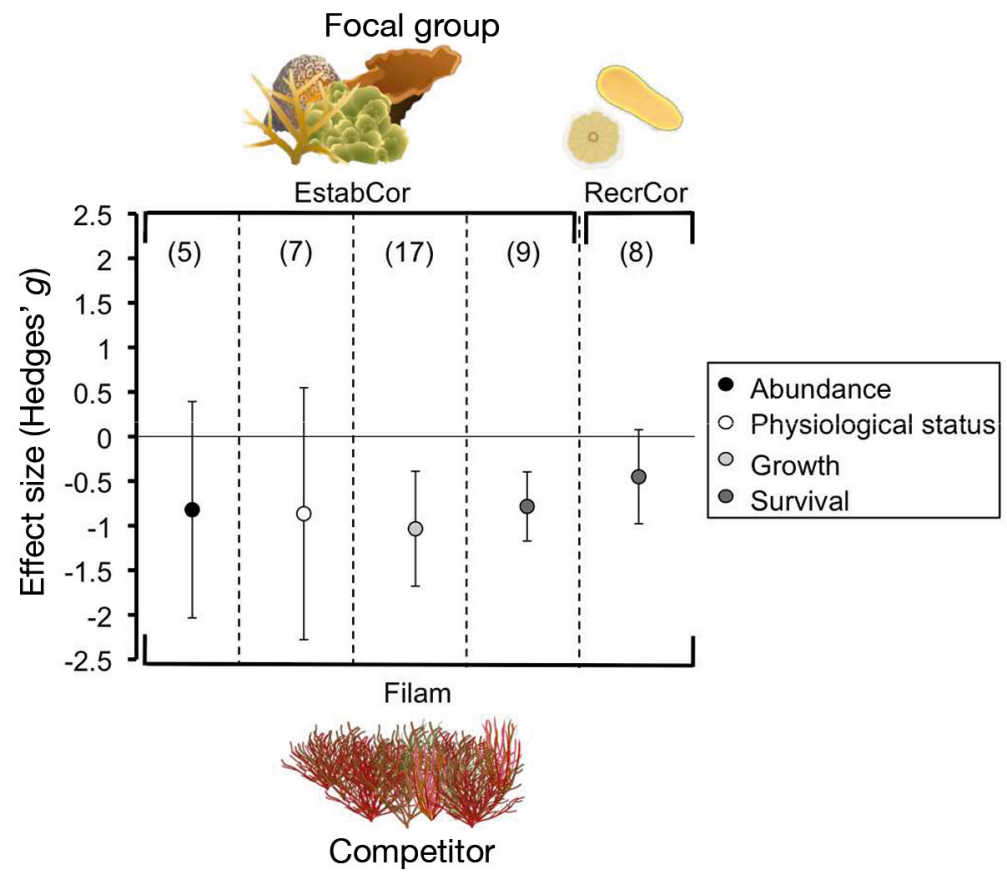

Fig. 4. Competitive effects (standardized mean difference) of filamentous (Filam) turf-forming algae (Competitor) on abundance, physiological status, growth, and survival of established corals or recruits (Focal groups: EstabCor, RecrCor). Data are mean effect sizes calculated from random effects models and $95 \%$ confidence intervals. Numbers of study-specific effect sizes contributing to each overall effect size are shown above the data points. Image credits: Tracey Saxby (Acropora, plate and encrusting coral, Chaetomorpha), Joanna Woerner (Porites lobata), Dieter Tracey (filamentous algae), and Diana Kleine (nonbranching filamentous algae). Integration and Application Network, University of Maryland Center for Environmental Science (ian.umces.edu/imagelibrary/) 




Fig. 5. Mechanisms of competition between reef-building corals and turf-forming algae. Turf algae inhibit early-life history stages of coral by (A) forming a settlement barrier to coral larvae and (B) overgrowth of small recruits. Established corals suppress turf algae (C) through shading, or (D) at the interaction zone through (1) space pre-emption, (2) overgrowth, and (3) digestion by mesenterial filaments. (E) Turf algae suppress established corals by (1) space pre-emption, (2) overgrowth, (3) allelopathy, and various turf-mediated physical and biological processes at the interaction zone described in detail in the text, including (4) releasing dissolved organic carbon, and (5) stimulating microbial and pathogenic activity. Image credits: Tracey Saxby (plate coral, Chaetomorpha), Dieter Tracey (filamentous algae), and Diana Kleine (nonbranching filamentous algae). Integration and Application Network, University of Maryland Center for Environmental Science (ian.umces.edu/imagelibrary/)

negative, albeit highly variable, effect on the abundance of turf algae (Fig. 1). This variability might be in part a consequence of the smaller number of studies contributing to the overall effect size in the latter case.
However, there also is considerable variation in relative competitive ability among different species (White \& O'Donnell 2010) and morphological groups of corals (Swierts \& Vermeij 2016), which may reflect disparities in the mechanisms of competition. Tabulate corals can shade turf algae (Fig. 5C; Baird \& Hughes 2000), and space pre-emption and turf overgrowth (Fig. 5D; McCook 2001, Diaz-Pulido \& McCook 2002, Barott et al. 2012b) are more effective forms of competition for encrusting and massive colonies than for branching corals (Swierts \& Vermeij 2016). Digestion of adjacent turf algae by mesenterial filaments (Fig. 5D) has been reported for some coral species experiencing bleaching, but the generality of this phenomenon is unknown (Marhaver 2011). Because of limitation in sample size, we grouped coral forms (e.g. branching, mounded, plate-like) under one category of established corals, but variation in coral composition among studies (Table S2 in the Supplement) likely contributes to increased variability of the mean effect.

The overall effect of filamentous turf algae on established corals across studies also was highly variable and depended on the response variable measured. While the mean effects were always negative in direction, these were only significant for growth and survival (Fig. 4). In contrast, effects on abundance and physiological status were highly variable and nonsignificant (Fig. 4). Again, this may reflect the comparatively fewer studies contributing to these effect sizes, or variability in competitive ability among coral species and growth forms. The mechanisms by which turf algae on coral reefs directly interact with and suppress competitors once established are more varied in comparison to temperate rocky reefs (Fig. 5E). Turf algae can pre-empt space or overgrow corals (Fig. 5E; Barott et al. 2012b, Gowan et al. 2014, Jorissen et al. 2016), but branching corals may be more susceptible to overgrowth than encrusting or massive colonies (Swierts \& Vermeij 2016). 
Alternatively, variable effects of different turf assemblages on corals between and within performance measures may result from differences in turf composition and physical structure. Some filamentous turf algae may produce allelopathic chemicals that cause bleaching and necrosis of coral tissue and facilitate overgrowth by turf (Fig. 5E), but this appears to be highly species specific (Jompa \& McCook $2003 a, b)$ and coral species vary in their susceptibility to these chemicals (Bonaldo \& Hay 2014). There are also a number of turf-mediated processes occurring at the coral-algae interaction zone that lead to bleaching, necrosis, and algal overgrowth of coral tissue, effects that are exacerbated with increasing height of the turf (Jorissen et al. 2016). Turf algae exude photosynthate (Fig. 5E; Haas et al. 2010), which stimulates microbial activity (Fig. 5E; Smith et al. 2006), increases abundance of pathogens (Barott et al. 2012a), decreases dissolved oxygen (Smith et al. 2006) and leads to hypoxia at night (Wangpraseurt et al. 2012, Jorissen et al. 2016). There is also an increase in the thickness of the diffusive boundary layer at the interaction zone, which could limit coral respiration and photosynthesis and promote the accumulation of allelochemicals and harmful metabolites (Wangpraseurt et al. 2012, Jorissen et al. 2016). Therefore, while there was an overall strong negative effect of established corals on tropical turfs, reciprocal effects of turf appear to be more context dependent, and the prevailing direction of the hierarchy may depend on factors that alter the standing biomass and species composition of turf.

\section{Relative importance of competition in mediating regime shifts}

Our results suggest regime shifts from foundation species to turf-forming algae could be mediated in part by changes to the competitive balance between these 2 groups. Evidence here illustrates that under ambient conditions, established brown algal canopies and coral colonies generally suppress turf algae, but that turf assemblages, particularly filamentous forms, can inhibit establishment of algal recruits or limit expansion of established corals. Patch occupancy models predict that an inferior competitor can exclude a superior competitor regionally if the probability of a superior competitor becoming established is lower in patches occupied by an inferior competitor than in unoccupied patches (i.e. the competitive hierarchy is not absolute), and the colonization rate of the inferior competitor is sufficiently high (Klausmeier \&
Tilman 2002). Therefore, factors that stimulate turf algae growth, and thereby increase standing biomass or colonization rate of open space, theoretically could lead to reef-scale declines in the abundance of foundation species. Filamentous algae generally have high maximum specific growth rates (Pedersen \& Borum 1996, Bokn et al. 2003) and rapid nutrient uptake rates (Pedersen \& Borum 1997), but specific data on the patch dynamics, rates of dispersal, colonization and vegetative propagation of turf assemblages are scarce (but see Airoldi 2000, Diaz-Pulido $\&$ McCook 2002). However, filamentous algae are often among the first colonists of open space on temperate (Hawkins \& Harkin 1985, Irving \& Connell 2006b) and tropical reefs (Woodley et al. 1981, Adjeroud et al. 2009).

Growth of turf algae can be stimulated by a number of factors modified by anthropogenic activity, which could increase the potential for competitionmediated regime shifts. Elevated nutrients in urbanized and eutrophic areas support increased growth rates (Pedersen \& Borum 1997, Lotze \& Schramm 2000) and abundance of temperate turf algae (Gorgula \& Connell 2004, Russell et al. 2009). However, heightened nutrient concentrations alone do not always stimulate turf growth and increase standing biomass on tropical reefs (Hatcher \& Larkum 1983, Larkum \& Koop 1997, Russ \& McCook 1999, Burkepile \& Hay 2006) because nutrient delivery and uptake are also mediated by water flow (Carpenter et al. 1991, Williams \& Carpenter 1998). Given their reliance on passive diffusion of $\mathrm{CO}_{2}$ in the absence or decreased efficiency of carbon concentrating mechanisms (Hepburn et al. 2011, Falkenberg et al. 2013), increased concentrations of $\mathrm{CO}_{2}$ associated with future ocean acidification also are expected to stimulate growth of tropical (Ober et al. 2016) and temperate (Connell \& Russell 2010) turf algae, particularly when combined with nutrient enrichment (Russell et al. 2009, Falkenberg et al. 2012). Tropical fish grazers also maintain turf assemblages at a low standing biomass (Hatcher \& Larkum 1983, Marshell \& Mumby 2015) and short height (Vermeij et al. 2010), but generally do not limit areal extent (Burkepile \& Hay 2006). Likewise, the abundance of temperate turf algae is enhanced by the removal of crustacean and molluscan grazers (Worm et al. 2001, Scheibling et al. 2009, Falkenberg et al. 2014). While the ability of grazers to counter the enriching effects of heightened nutrients and $\mathrm{CO}_{2}$ is variable (Worm et al. 2001, Vermeij et al. 2010, Ghedini et al. 2015), the highest rates of turf algae growth, and greatest potential for competition-mediated regime shifts, can be expected 
when enrichment is combined with weak top-down control where grazing intensity is naturally low or reduced by overfishing.

Increased spatial dominance of turf algae also could occur without invoking changes to competitive hierarchies if increasing stress and disturbance disproportionately afflict canopy algae or corals. This may be the case if there is a trade-off between competitive ability and stress tolerance (Keddy 2001), vulnerability to disturbance (Dayton et al. 1984), or colonization rate (Sousa 1979). Anthropogenic influences that act as a resource to turf algae can also be a form of disruptive stress to foundation species. For example, increased oceanic uptake of $\mathrm{CO}_{2}$ benefits tropical turf algae (Ober et al. 2016), but consequent acidification impedes calcification rates and growth of reef-building corals (Gattuso et al. 1998, Jokiel et al. 2008). Further, while warming seawater temperatures can synergistically enhance turf algae growth in response to $\mathrm{CO}_{2}$ enrichment (Connell \& Russell 2010), they also may impose chronic stress on canopy algae (Wernberg et al. 2010, Simonson et al. 2015) and corals (Carricart-Ganivet et al. 2012), or generate disturbance in the form of pulse events such as heat waves (Smale \& Wernberg 2013, Wernberg et al. 2016), El Niño (McClanahan et al. 2001), and other sea surface temperature anomalies (Eakin et al. 2010). Likewise, sedimentation is often a form of stress or disturbance for established corals (Rogers 1990, Nugues \& Roberts 2003), and for early lifehistory stages of coral (Birkeland 1977, Birrell et al. 2005) and canopy algae (Devinny \& Volse 1978). However, turf algae commonly tolerate high sediment loads (Airoldi 1998, Connell 2005, Eriksson \& Johansson 2005) and even exacerbate the effects of sedimentation on foundation species by binding and accumulating sediments through a reduction in along-bottom flow (Purcell 2000, Gorman \& Connell 2009, Filbee-Dexter et al. 2016). Physical disturbances such as hurricanes and tropical cyclones (Gardner et al. 2005, Osborne et al. 2011, Filbee-Dexter \& Scheibling 2012), and biological disturbances such as outbreaks of crown-of-thorns starfish (Osborne et al. 2011) or coral disease (Aronson \& Precht 2001), and tissue loss induced by heavy fouling of canopy algae (Scheibling et al. 1999) also cause large-scale removal or mortality of foundation species. Moreover, anthropogenic impacts that cause disruptive stress may increase the effective intensity of such disturbances by prolonging recovery times (Gaylord et al. 2015).

Large disturbance events may likewise intensify the effects of stress on foundation species if decreas- ing adult density results in a loss of positive interactions. Algal canopies ameliorate physical stress from high light intensity, promoting increased adult growth (Bennett et al. 2015a). Furthermore, movement of fronds across the bottom limits sediment accumulation (Connell 2005, Wernberg et al. 2005, Irving \& Connell 2006b) and temperature-mediated epiphyte growth, which facilitates recruitment of canopy algae (Bennett \& Wernberg 2014). Other density-dependent processes that inhibit recovery of foundation species and indirectly benefit turf algae may likewise facilitate regime shifts, rather than competition. The large increase in open space associated with coral mortality greatly expands the foraging area for herbivores and effectively decreases grazing rate per unit area of substratum (Williams et al. 2001). Conversely, on temperate reefs a low density of canopy algae can intensify grazing on remaining individuals (O'Brien et al. 2015) or new recruits (Bennett et al. 2015b). Recruitment limitation following loss of adults also may arise from a dwindling supply of propagules and concomitant supply-side constraints on tropical (Hughes et al. 2000, Vermeij \& Sandin 2008) and temperate reefs (Bennett \& Wernberg 2014, O'Brien \& Scheibling 2016).

\section{Conclusions and future directions}

Through this synthesis of the literature from tropical and temperate reefs we have shown that corals and canopy algae consistently exert a negative effect on the abundance of turf-forming algae, but that the competitive effect of turf algae depends on the functional form of turf and life-history stage of the interacting foundation species. Moreover, variability in the effect of competitors can often be interpreted in light of the competitive mechanisms at play. Since the predominant effect of turf algae is to limit the establishment of canopy algae or expansion of established corals, it is possible that factors stimulating turf growth and expansion alone (decreased herbivory, nutrient enrichment, increased $\mathrm{CO}_{2}$ ) may shift the competitive balance in favour of turf, resulting in reefs that are depauperate of corals or canopy algae. However, factors that stimulate turf growth are often concomitant with anthropogenic stressors or disturbances to foundation species (Gorman et al. 2009, Rocha et al. 2015) that may benefit turf algae indirectly. Our results suggest competition plays a role in mediating regime shifts from foundation to turf-forming species, but it remains to be seen if the main effect of anthropogenic stressors is promoting the 
growth of turf (shifting the balance between competitors) or reducing the abundance of foundation species (disproportionately limiting one competitor). The reality likely falls somewhere in between, where recovery of foundation species following adult losses is made increasingly difficult by proliferating turf algae that limit recruitment of canopy algae or expansion of residual coral colonies.

To accurately parse the relative importance of competition, stress, and disturbance requires more factorial competition experiments in the field and laboratory. These ecological processes do not operate independently. Few studies included in this analysis were factorial experiments that tested interactions of competition with herbivory, nutrient or $\mathrm{CO}_{2}$ enrichment, or other forms of stress and disturbance that potentially mediate competitive interactions (Table S3). Experiments conducted along natural gradients in the field also will be useful in this respect, and have revealed the existence of gradients in competition intensity in terrestrial ecosystems (Keddy 2001). Only 4 studies included here aimed to replicate experiments in space or time to make use of natural gradients (McCook 2001, Venera-Ponton et al. 2011, Corado-Nava et al. 2014, Barner et al. 2016). Furthermore, many competition experiments are often conducted on relatively short time scales (Table S3) following pulse removals. Since there may be a divergence between the short-term dynamics of small-scale interactions and the long-term outcome of competition on a reef scale, it would be beneficial to extend experiments across multiple years and synthesize observational/correlative studies as well to extend generality.

While it is not always feasible to conduct field experiments on the relevant spatial and temporal scales, especially when there are multiple crossed factors, spatial (e.g. interacting particle systems) and dynamic models will be useful in this regard. Models that take into account competitive effects are powerful tools that allow ecologists to predict the equilibrium abundance of foundation species like corals and canopy algae at increasing levels of external forcing variables (e.g. grazing pressure, nutrient input, sedimentation, temperature). As such, they provide a platform to explore the integrative effects of competition, disturbance, and stress. Importantly, they can identify the levels of the forcing variables at which abrupt changes in abundance can be expected, and reveal whether such changes may be easily reversed by returning the forcing variable to below the level where the shift occurred (i.e. whether the regime shift is continuous or discontinuous). Such models have been applied to regime shifts in response to coral reef degradation (Mumby 2009, Fung et al. 2011), but typically assume minimal or no effects of turf algae. Furthermore, we have shown that grouping the competitive effects of turf into one functional group will not accurately capture the dynamics of competition. Improved estimates of the magnitude and direction of the effects of foundation and turfforming species, the associated uncertainty, and systematic sources of variability will improve the utility of such models to evaluate the stability of these undesirable regime shifts and potential for recovery under alternative climate and management scenarios.

Acknowledgements. We thank H. Lotze, S. Walde, M. Wong, A. MacNeil, K. Filbee-Dexter, D. Lyons, K. Krumhansl, and 2 anonymous reviewers for helpful comments on earlier drafts of this manuscript. This research was funded by a Discovery Grant to R.E.S. from the Natural Sciences and Engineering Research Council (NSERC) of Canada. J.M.O. was supported by a Dalhousie Killam Scholarship, an NSERC Canada Graduate Scholarship, a Nova Scotia Graduate Scholarship, and a Dalhousie President's Award.

\section{LITERATURE CITED}

Adjeroud M, Michonneau F, Edmunds PJ, Chancerelle Y and others (2009) Recurrent disturbances, recovery trajectories, and resilience of coral assemblages on a South Central Pacific reef. Coral Reefs 28:775-780

Airoldi L (1998) Roles of disturbance, sediment stress, and substratum retention on spatial dominance in algal turf. Ecology 79:2759-2770

Airoldi L (2000) Responses of algae with different life histories to temporal and spatial variability of disturbance in subtidal reefs. Mar Ecol Prog Ser 195:81-92

Alestra T, Tait LW, Schiel DR (2014) Effects of algal turfs and sediment accumulation on replenishment and primary productivity of fucoid assemblages. Mar Ecol Prog Ser 511:59-76

Aronson RB, Precht WF (2001) White-band disease and the changing face of Caribbean coral reefs. Hydrobiologia 460:25-38

Baird AH, Hughes TP (2000) Competitive dominance by tabular corals: an experimental analysis of recruitment and survival of understorey assemblages. J Exp Mar Biol Ecol 251:117-132

Bak RPM, Engel MS (1979) Distribution, abundance, and survival of juvenile hermatypic corals (Scleractinia) and the importance of life history strategies in the parent coral community. Mar Biol 54:341-352

Ban SS, Graham NAJ, Connolly SR (2014) Evidence for multiple stressor interactions and effects on coral reefs. Glob Change Biol 20:681-697

Barner AK, Hacker SD, Menge BA, Neilsen KJ (2016) The complex net effect of reciprocal interactions and recruitment facilitation maintains an intertidal kelp community. J Ecol 104:33-43

Barott KL, Rodriguez-Mueller B, Youle M, Marhaver KL, Vermeij MJA, Smith JE, Rohwer FL (2012a) Microbial to reef scale interactions between the reef-building coral Montastraea annularis and benthic algae. Proc R Soc B 


\section{9:1655-1664}

Barott KL, Williams GJ, Vermeij MJA, Harris J, Smith JE, Rohwer FL, Sandin SA (2012b) Natural history of coralalgae competition across a gradient of human activity in the Line Islands. Mar Ecol Prog Ser 460:1-12

Bellgrove A, McKenzie PF, Mckenzie JL, Sfiliagoj B (2010) Restoration of the habitat-forming fucoid alga Hormosira banksii at effluent-affected sites: competitive exclusion by coralline turfs. Mar Ecol Prog Ser 419:47-56

Benedetti-Cecchi L, Cinelli F (1992) Effects of canopy cover, herbivores and substratum type on patterns of Cystoseira spp. settlement and recruitment in littoral rockpools. Mar Ecol Prog Ser 90:183-191

Benedetti-Cecchi L, Nuti S, Cinelli F (1996) Analysis of spatial and temporal variability in interactions among algae, limpets and mussels in low-shore habitats on the west coast of Italy. Mar Ecol Prog Ser 144:87-96

Benedetti-Cecchi L, Pannacciulli F, Bulleri F, Moschella PS, Airoldi L, Relini G, Cinelli F (2001) Predicting the consequences of anthropogenic disturbance: large-scale effects of loss of canopy algae on rocky shores. Mar Ecol Prog Ser 214:137-150

Bennett S, Wernberg T (2014) Canopy facilitates seaweed recruitment on subtidal temperate reefs. J Ecol 102: 1462-1470

Bennett S, Wernberg $T$, de Bettignies $T$, Kendrick GA, Anderson RJ (2015a) Canopy interactions and physical stress gradients in subtidal communities. Ecol Lett 18: 677-686

Bennett S, Wernberg T, Harvey ES, Santana-Garcon J, Saunders BJ (2015b) Tropical herbivores provide resilience to a climate-mediated phase shift on temperate reefs. Ecol Lett 18:714-723

Berger R, Henriksson E, Kautsky L, Malm T (2003) Effects of filamentous algae and deposited matter on the survival of Fucus vesiculosus L. germlings in the Baltic Sea. Aquat Ecol 37:1-11

Bertness MD, Callaway R (1994) Positive interactions in communities. Trends Ecol Evol 9:191-193

Birkeland C (1977) The importance of rate of biomass accumulation in early successional stages of benthic communities to the survival of coral recruits. Proc 3rd Int Coral Reef Symp Miami, FL 1:15-21

Birrell CL, McCook LJ, Willis BL (2005) Effects of algal turfs and sediment on coral settlement. Mar Pollut Bull 51: 408-414

Bokn T, Duarte CM, Pedersen MF, Marba N, Moy FE (2003) The response of experimental rocky shore communities to nutrient additions. Ecosystems 6:577-594

Bonaldo RM, Hay ME (2014) Seaweed-coral interactions: variance in seaweed allelopathy, coral susceptibility, and potential effects on coral resilience. PLOS ONE 9:e85786

Borenstein M, Hedges LV, Higgins JPT, Rothstein HR (2009) Introduction to meta-analysis. John Wiley \& Sons, Chichester

Brawley SH, Johnson LE (1991) Survival of fucoid embryos in the intertidal zone depends upon developmental stage and microhabitat. J Phycol 27:179-186

Bruno JF, Sweatman H, Precht WF, Selig ER, Schutte VGW (2009) Assessing evidence of phase shifts from coral to macroalgal dominance on coral reefs. Ecology 90: 1478-1484

Burkepile DE, Hay ME (2006) Herbivore vs. nutrient control of marine primary producers: context-dependent effects. Ecology 87:3128-3139
Carpenter RC (1985) Relationships between primary production and irradiance in coral reef algal communities. Limnol Oceanogr 30:784-793

Carpenter RC, Hackney JM, Adey WH (1991) Measurements of primary productivity and nitrogenase activity of coral reef algae in a chamber incorporating oscillatory flow. Limnol Oceanogr 36:40-49

* Carricart-Ganivet JP, Cabanillas-Terán N, Cruz-Ortega I, Blanchon P (2012) Sensitivity of calcification to thermal stress varies among genera of massive reef-building corals. PLOS ONE 7:e32859

* Cervin G, Åberg P, Jenkins SR (2005) Small-scale disturbance in a stable canopy dominated community: implications for macroalgal recruitment and growth. Mar Ecol Prog Ser 305:31-40

Connell SD (2005) Assembly and maintenance of subtidal habitat heterogeneity: synergistic effects of light penetration and sedimentation. Mar Ecol Prog Ser 289:53-61

Connell SD, Russell BD (2010) The direct effects of increasing $\mathrm{CO}_{2}$ and temperature on non-calcifying organisms: increasing the potential for phase shifts in kelp forests. Proc R Soc B 277:1409-1415

Connell SD, Russell BD, Turner DJ, Shepherd SA and others (2008) Recovering a lost baseline: missing kelp forests from a metropolitan coast. Mar Ecol Prog Ser 360:63-72

Connell SD, Russell BD, Irving AD (2011) Can strong consumer and producer effects be reconciled to better forecast 'catastrophic' phase-shifts in marine ecosystems? J Exp Mar Biol Ecol 400:296-301

* Connell SD, Kroeker KJ, Fabricus KE, Kline DI, Russell BD (2013) The other ocean acidification problem: $\mathrm{CO}_{2}$ as a resource among competitors for ecosystem dominance. Philos Trans R Soc Lond B Biol Sci 368:20120442

Connell SD, Foster MS, Airoldi L (2014) What are algal turfs? Towards a better description of turfs. Mar Ecol Prog Ser 495:299-307

Conversi A, Dakos V, Gårdmark A, Ling S and others (2015) A holistic view of marine regime shifts. Philos Trans R Soc Lond B Biol Sci 370:20130279

Corado-Nava NA, Rodríguez D, Rivas G (2014) Algal turfs colonization effect on Pocillopora capitata (Anthozoa: Scleractinia) growth at Mexican tropical Pacific. Rev Mex Biodivers 85:1086-1092

Davison IR, Pearson GA (1996) Stress tolerance in intertidal seaweeds. J Phycol 32:197-211

Dayton PK (1972) Towards an understanding of community resilience and the potential effects of enrichment to the benthos at McMurdo Sound, Antarctica. In: Parker BC (ed) Proc Colloquium on Conservation Problems in Antarctica. Allen Press, Lawrence, KS, p 81-96

* Dayton PK (1975) Experimental evaluation of ecological dominance in a rocky intertidal algal community. Ecol Monogr 45:137-159

*Dayton PK, Currie V, Gerrodette T, Keller BD, Rosenthal R, Ven Tresca D (1984) Patch dynamics and stability of some California kelp communities. Ecol Monogr 54:253-289

* Deiman M, Iken K, Konar B (2012) Susceptibility of Nereocystis luetkeana (Laminariales, Ochrophyta) and Eualaria fistulosa (Laminariales, Ochrophyta) spores to sedimentation. Algae 27:115-123

* DerSimonian R, Laird NM (1986) Meta-analysis in clinical trials. Control Clin Trials 7:177-188

*Devinny JS, Volse LA (1978) Effects of sediments on the development of Macrocystis pyrifera gametophytes. Mar Biol 48:343-348 
Diaz-Pulido G, McCook LJ (2002) The fate of bleached corals: patterns and dynamics of algal recruitment. Mar Ecol Prog Ser 232:115-128

* Dijkstra JA, Harris LG, Mello K, Litterer A, Wells C, Ware C (2017) Invasive seaweeds transform habitat structure and increase biodiversity of associated species. J Ecol. doi:10.1111/1365-2745.12775

* Dixson DL, Abrego D, Hay ME (2014) Chemically mediated behavior of recruiting corals and fishes: a tipping point that may limit reef recovery. Science 345:892-897

Eakin CM, Morgan JA, Heron SF, Smith TB, and others (2010) Caribbean corals in crisis: record thermal stress, bleaching, and mortality in 2005. PLOS ONE 5:e13969

Eriksson BK, Johansson G (2005) Effects of sedimentation on macroalgae: species-specific responses are related to reproductive traits. Oecologia 143:438-448

Falkenberg LJ, Russell BD, Connell SD (2012) Stability of strong species interactions resist the synergistic effects of local and global pollution in kelp forest. PLOS ONE 7: e33841

Falkenberg LJ, Russell BD, Connell SD (2013) Contrasting resource limitations of marine primary producers: implications for competitive interactions under enriched $\mathrm{CO}_{2}$ and nutrient regimes. Oecologia 172:575-583

Falkenberg LJ, Connell SD, Russell BD (2014) Herbivory mediates the expansion of an algal habitat under nutrient and $\mathrm{CO}_{2}$ enrichment. Mar Ecol Prog Ser 497:87-92

Filbee-Dexter K, Scheibling RE (2012) Hurricane-mediated defoliation of kelp beds and pulsed delivery of kelp detritus to offshore sedimentary habitats. Mar Ecol Prog Ser 455:51-64

Filbee-Dexter K, Wernberg T (2018) The rise of turfs: a new battlefront for globally declining kelp forests. Bioscience. doi:10.1093/biosci/bix147

Filbee-Dexter K, Feehan CJ, Scheibling RE (2016) Largescale degradation of a kelp ecosystem in an ocean warming hotspot. Mar Ecol Prog Ser 543:141-152

Fung T, Seymour RM, Johnson CR (2011) Alternative stable states and phase shifts in coral reefs under anthropogenic stress. Ecology 92:967-982

* Gardner TA, Côté IM, Gill J, Grant A, Watkinson AR (2005) Hurricanes and Caribbean coral reefs: impacts, recovery, patterns, and role in long-term decline. Ecology 86: 174-184

Gattuso JP, Frankignoulle M, Bourge I, Romaine S, Buddemeier RW (1998) Effect of calcium carbonate saturation of seawater on coral calcification. Global Planet Change 18:37-46

Gaylord B, Kroeker KJ, Sunday JM, Anderson KM, Barry JP (2015) Ocean acidification through the lens of ecological theory. Ecology 96:3-15

Ghedini G, Russell BD, Connell SD (2015) Trophic compensation reinforces resistance: herbivory absorbs the increasing effects of multiple disturbances. Ecol Lett 18: 182-187

Gorgula SK, Connell SD (2004) Expansive covers of turfforming algae on human-dominated coast: the relative effects of increasing nutrient and sediment loads. Mar Biol 145:613-619

* Gorman D, Connell SD (2009) Recovering subtidal forests in human-dominated landscapes. J Appl Ecol 46:1258-1265

* Gorman D, Russell BD, Connell SD (2009) Land-to-sea connectivity: linking human-derived terrestrial subsidies to subtidal habitat change on open rocky coasts. Ecol Appl 19:1114-1126
Gowan JC, Tootell JS, Carpenter RC (2014) The effects of water flow and sedimentation on interactions between massive Porites and algal turf. Coral Reefs 33:651-663

Grime JP (1977) Evidence for the existence of three primary strategies in plants and its relevance to ecological and evolutionary theory. Am Nat 111:1169-1194

* Haas A, el-Zibdah M, Wild C (2010) Seasonal monitoring of coral-algae interactions in fringing reefs of the Gulf of Aqaba, Northern Red Sea. Coral Reefs 29:93-103

*Häder DP, Lebert M, Helbling EW (2003) Effects of solar radiation on the Patagonian rhodophyte Corallina officinalis (L.). Photosynth Res 78:119-132

Harris LG, Ebeling AW, Laur DR, Rowley RJ (1984) Community recovery after storm damage: a case of facilitation in primary succession. Science 224:1336-1338

*Harris JL, Lewis LS, Smith JE (2015) Quantifying scales of spatial variability in algal turf assemblages on coral reefs. Mar Ecol Prog Ser 532:41-57

Hatcher BG, Larkum AWD (1983) An experimental analysis of factors controlling the standing crop of the epilithic algal community on a coral reef. J Exp Mar Biol Ecol 69: 61-84

* Hawkins SJ, Harkin E (1985) Preliminary canopy removal experiments in algal dominated communities low on the shore in the shallow subtidal on the Isle of Man. Bot Mar 28:223-230

* Hay ME (1981) The functional morphology of turf-forming seaweeds: persistence in stressful marine habitats. Ecology 62:739-750

Hedges LV, Olkin I (1985) Statistical methods for metaanalysis. Academic Press, San Diego, CA

*Hepburn CD, Pritchard DW, Cornwall CE, McLeod RJ, Beardall J, Raven JA, Hurd CL (2011) Diversity of carbon use strategies in a kelp forest community: implications for a high $\mathrm{CO}_{2}$ ocean. Glob Change Biol 17:2488-2497

* Hughes TP, Baird AH, Dinsdale EA, Moltschaniwskyj NA, Pratchett MS, Tanner JE, Willis BL (2000) Supply-side ecology works both ways: the link between benthic adults, fecundity, and larval recruits. Ecology 81:2241-2249

* Irving AD, Connell SD (2006a) Physical disturbance by kelp abrades erect algae from the understorey. Mar Ecol Prog Ser 324:127-137

* Irving AD, Connell SD (2006b) Predicting understorey structure from the presence and composition of canopies: an assembly rule for marine algae. Oecologia 148:491-502

“ Isæus M, Malm T, Persson S, Svensson A (2004) Effects of filamentous algae and sediment on recruitment and survival of Fucus serratus (Phaeophyceae) juveniles in the eutrophic Baltic Sea. Eur J Phycol 39:301-307

*Jackson GA, Winant CD (1983) Effect of a kelp forest on coastal currents. Cont Shelf Res 2:75-80

Jennions MD, Christopher CJ, Rosenberg MS, Rothstein HR (2013) Publication and related bias. In: Koricheva J, Gurevitch J, Mengersen K (eds) Handbook of metaanalysis in ecology and evolution. Princeton University Press, Princeton, NJ, p 207-236

Johnson CR, Mann KH (1988) Diversity, patterns of adaptation, and stability of Nova Scotian kelp beds. Ecol Monogr 58:129-154

Jokiel PL, Rodgers KS, Kuffner IB, Andersson AJ, Cox EF, Mackenzie FT (2008) Ocean acidification and calcifying reef organisms: a mesocosm investigation. Coral Reefs 27:473-483

Jompa J, McCook LJ (2003a) Contrasting effects of turf algae on corals: massive Porites spp. are unaffected by 
mixed-species turfs, but killed by the red alga Anotrichium tenue. Mar Ecol Prog Ser 258:79-86

Jompa J, McCook LJ (2003b) Coral-algal competition: macroalgae with different properties have different effects on corals. Mar Ecol Prog Ser 258:87-95

Jorissen H, Skinner C, Osinga R, de Beer D, Nugues MM (2016) Evidence for water-mediated mechanisms in coral-algal interactions. Proc R Soc B 283:20161137

Keddy PA (2001) Competition, 2nd edn. Kluwer Academic Publishers, Boston, MA

Kiirikki M (1996) Experimental evidence that Fucus vesiculosus (Phaeophyta) controls filamentous algae by means of the whiplash effect. Eur J Phycol 31:61-66

Kim JH (2002) Mechanisms of competition between canopyforming and turf-forming intertidal algae. Algae 17:33-39

Klausmeier CA, Tilman D (2002) Spatial models of competition. In: Sommer U, Worm B (eds) Competition and coexistence. Springer, New York, NY, p 43-78

Klumpp DW, McKinnon AD (1992) Community structure, biomass and productivity of epilithic algal communities on the Great Barrier Reef: dynamics at different spatial scales. Mar Ecol Prog Ser 86:77-89

Knowlton N (1992) Thresholds and multiple stable states in coral reef community dynamics. Am Zool 32:674-682

Larkum AWD, Koop K (1997) ENCORE, algal productivity and possible paradigm shifts. Proc 8th Int Coral Reef Symp, Panama 1:881-884

Lotze H, Schramm W (2000) Ecophysiological traits explain species dominance patterns in macroalgal blooms. J Phycol 36:287-295

Marhaver KL (2011) Bleaching corals of two species appear to feed from neighbouring algal turfs. Coral Reefs 30:651

* Marshell A, Mumby PJ (2015) The role of surgeonfish (Acanthuridae) in maintaining algal turf biomass on coral reefs. J Exp Mar Biol Ecol 473:152-160

McClanahan TR, Muthiga NA, Mangi S (2001) Coral and algal changes after the 1998 coral bleaching: interaction with reef management and herbivores on Kenyan reefs. Coral Reefs 19:380-391

McCook LJ (2001) Competition between corals and algal turfs along a gradient of terrestrial influence in the nearshore central Great Barrier Reef. Coral Reefs 19:419-425

McCook LJ, Jompa J, Diaz-Pulido G (2001) Competition between corals and algae on coral reefs: a review of evidence and mechanisms. Coral Reefs 19:400-417

Mellin C, MacNeil MA, Cheal AJ, Emslie MJ, Caley MJ (2016) Marine protected areas increase resilience among coral reef communities. Ecol Lett 19:629-637

Milligan KLD, DeWreede RE (2000) Variations in holdfast attachment mechanics with developmental stage, substratum-type, season, and wave-exposure for the intertidal kelp species Hedophyllum sessile (C. Agardh) Setchell. J Exp Mar Biol Ecol 254:189-209

Möllmann C, Folke C, Edwards M, Conversi A (2015) Marine regime shifts around the globe: theory, drivers and impacts. Philos Trans R Soc Lond B Biol Sci 370:20130260

Moy FE, Christie H (2012) Large-scale shift from sugar kelp (Saccharina latissima) to ephemeral algae along the south and west coast of Norway. Mar Biol Res 8:309-321

Mumby PJ (2009) Phase shifts and the stability of macroalgal communities on Caribbean coral reefs. Coral Reefs 28: 761-773

Nugues MM, Roberts CM (2003) Coral mortality and interaction with algae in relation to sedimentation. Coral Reefs 22:507-516
O'Brien JM, Scheibling RE (2016) Nipped in the bud: mesograzer feeding preference contributes to kelp decline. Ecology 97:1873-1886

* O'Brien JM, Scheibling RE, Krumhansl KA (2015) Positive feedback between large-scale disturbance and densitydependent grazing decreases resilience of a kelp bed ecosystem. Mar Ecol Prog Ser 522:1-13

Ober GT, Diaz-Pulido G, Thornber C (2016) Ocean acidification influences the biomass and diversity of reef-associated turf algal communities. Mar Biol 163:204

Osborne K, Dolman AM, Burgess SC, Johns KA (2011) Disturbance and the dynamics of coral cover on the Great Barrier Reef (1995-2009). PLOS ONE 6:e17516

*Pedersen MF, Borum J (1996) Nutrient control of algal growth in estuarine waters. Nutrient limitation and the importance of nitrogen requirements and nitrogen storage among phytoplankton and species of macroalgae. Mar Ecol Prog Ser 142:261-272

* Pedersen MF, Borum J (1997) Nutrient control of estuarine macroalgae: growth strategy and the balance between nitrogen requirements and uptake. Mar Ecol Prog Ser 161:155-163

Purcell SW (2000) Association of epilithic algae with sediment distribution on a windward reef in the northern Great Barrier Reef, Australia. Bull Mar Sci 66: $199-214$

R Core Team (2015) R: a language and environment for statistical computing. R Foundation for Statistical Computing, Vienna

* Råberg S, Berger-Jönsson R, Björn A, Granéli E, Kautsky L (2005) Effects of Pilayella littoralis on Fucus vesiculosus recruitment: implications for community composition. Mar Ecol Prog Ser 289:131-139

* Rocha J, Yletyinen J, Biggs R, Blenckner T, Peterson G (2015) Marine regime shifts: drivers and impacts on ecosystems services. Philos Trans R Soc Lond B Biol Sci 370: 20130273

Kogers CS (1990) Responses of coral reefs and reef organisms to sedimentation. Mar Ecol Prog Ser 62:185-202

* Rosenberg MS (2005) The file-drawer problem revisted: a general weighted method for calculating fail-safe numbers in meta-analysis. Evolution 59:464-468

Rosenthal R (1979) The 'file drawer problem' and tolerance for null results. Psychol Bull 86:638-641

* Russ GR, McCook LJ (1999) Potential effects of a cyclone on benthic algal production and yield to grazers on coral reefs across the central Great Barrier Reef. J Exp Mar Biol Ecol 235:237-254

Russell BD (2007) Effects of canopy-mediated abrasion and water flow on the early colonisation of turf-forming algae. Mar Freshw Res 58:657-665

Russell BD, Thompson JI, Falkenberg LJ, Connell SD (2009) Synergistic effects of climate change and local stressors: $\mathrm{CO}_{2}$ and nutrient-driven change in subtidal rocky habitats. Glob Change Biol 15:2153-2162

* Scheffer M, Carpenter SR, Foley JA, Folke C, Walker B (2001) Catastrophic shifts in ecosystems. Nature 413: 591-596

* Scheibling RE, Hennigar AW, Balch T (1999) Destructive grazing, epiphytism, and disease: the dynamics of sea urchin-kelp interactions in Nova Scotia. Can J Fish Aquat Sci 56:2300-2314

Scheibling RE, Kelly NE, Raymond BG (2009) Herbivory and community organization on a subtidal cobble bed. Mar Ecol Prog Ser 382:113-128 
Schiel DR, Wood SA, Dunmore RA, Taylor DI (2006) Sediment on rocky intertidal reefs: Effects on early post-settlement stages of habitat-forming seaweeds. J Exp Mar Biol Ecol 331:158-172

Simonson EJ, Scheibling RE, Metaxas A (2015) Kelp in hot water: I. Warming seawater temperature induces weakening and loss of kelp tissue. Mar Ecol Prog Ser 537:89-104

Smale DA, Wernberg T (2013) Extreme climatic event drives range contraction of a habitat-forming species. Proc $\mathrm{R}$ Soc B 280:20122829

Smith JE, Shaw M, Edwards RA, Obura D, and others (2006) Indirect effects of algae on coral: algae-mediated, microbeinduced coral mortality. Ecol Lett 9:835-845

Sousa WP (1979) Experimental investigations of disturbance and ecological succession in a rocky intertidal algal community. Ecol Monogr 49:227-254

Steen H (2004) Interspecific competition between Enteromorpha (Ulvales: Chlorophyceae) and Fucus (Fucales: Phaeophyceae) germlings: effects of nutrient concentration, temperature, and settlement density. Mar Ecol Prog Ser 278:89-101

Steneck RS, Dethier MN (1994) A functional group approach to the structure of algal-dominated communities. Oikos 69:476-498

Strain EMA, Thomson RJ, Micheli F, Mancuso FP, Airoldi L (2014) Identifying the interacting roles of stressors in driving the global loss of canopy-forming to mat-forming algae in marine ecosystems. Glob Change Biol 20: 3300-3312

Svensson JR, Nylund GM, Cervin G, Toth GB, Pavia H (2013) Novel chemical weapon of an exotic macroalga inhibits recruitment of native competitors in the invaded range. J Ecol 101:140-148

Swierts T, Vermeij MJA (2016) Competitive interactions between corals and turf algae depend on coral colony form. PeerJ 4:e1984

Toohey B, Kendrick GA, Wernberg T, Phillips JC, Malkin S, Prince J (2004) The effects of light and thallus scour from Ecklonia radiata canopy on an associated foliose algal assemblage: the importance of photoacclimation. Mar Biol 144:1019-1027

Vadas RL, Wright WA, Miller SL (1990) Recruitment of Ascophyllum nodosum: wave action as a source of mortality. Mar Ecol Prog Ser 61:263-272

Venera-Ponton DE, Diaz-Pulido G, McCook LJ, RangelCampo A (2011) Macroalgae reduce growth of juvenile corals but protect them from parrotfish damage. Mar Ecol Prog Ser 421:109-115

Vermeij MJA, Sandin SA (2008) Density-dependent settlement and mortality structure the earliest life phases of a coral population. Ecology 89:1994-2004

Vermeij MJA, van Moorselaar I, Engelhard S, Hörnlein C, Vonk SM, Visser PM (2010) The effects of nutrient

Editorial responsibility: Morten Pedersen,

Roskilde, Denmark enrichment and herbivore abundance on the ability of turf algae to overgrow coral in the Caribbean. PLOS ONE 5:e14312

* Viechtbauer W (2010) Conducting meta-analyses in R with the metafor package. J Stat Softw 36:1-48

Wangpraseurt D, Weber M, Røy H, Polerecky L, de Beer D, Suharsono, Nugues MM (2012) In situ oxygen dynamics in coral-algal interactions. PLOS ONE 7:e31192

Wernberg $\mathrm{T}$ and others (2016) Climate-driven regime shift of a temperate marine ecosystem. Science 353:169-172

Wernberg T, Kendrick GA, Toohey BD (2005) Modification of the physical environment by an Ecklonia radiata (Laminariales) canopy and implications for associated foliose algae. Aquat Ecol 39:419-430

* Wernberg T, Thomsen M, Tuya F, Kendrick GA, Staehr PA, Toohey BD (2010) Decreasing resilience of kelp beds along a latitudinal temperature gradient: potential implications for a warmer future. Ecol Lett 13:685-694

White JSS, O'Donnell JL (2010) Indirect effects of a key ecosystem engineer alter survival and growth of foundation coral species. Ecology 91:3538-3548

Wild C, Jantzen C, Kremb SG (2014) Turf algae-mediated coral damage in coastal reefs of Belize, Central America. PeerJ 2:e571

Williams SL, Carpenter RC (1998) Effects of unidirectional and oscillatory water flow on nitrogen fixation (acetylene reduction) in coral reef algal turfs, Kaneohe Bay, Hawaii. J Exp Mar Ecol Biol 226:293-316

Williams ID, Polunin NVC, Hendrick VJ (2001) Limits to grazing by herbivorous fishes and the impact of low coral cover on macroalgal abundance on a coral reef in Belize. Mar Ecol Prog Ser 222:187-196

Wismer S, Hoey AS, Bellwood DR (2009) Cross-shelf benthic community structure on the Great Barrier Reef: relationships between macroalgal cover and herbivore biomass. Mar Ecol Prog Ser 376:45-54

Woodley JD, Chornesky EA, Clifford PA, Jackson JBC and others (1981) Hurricane Allen's impact on Jamaican coral reefs. Science 214:749-755

* Worm B, Chapman ARO (1998) Relative effects of elevated grazing pressure and competition from a red algal turf on two post-settlement stages of Fucus evanescens C. Ag. J Exp Mar Biol Ecol 220:247-268

Worm B, Karez R (2002) Competition, coexistence, and diversity on rocky shores. In: Sommer U, Worm B (eds) Competition and coexistence. Springer, New York, NY, p 132-163

*Worm B, Sommer U (2000) Rapid direct and indirect effects of a single nutrient pulse in a seaweed-epiphyte-grazer system. Mar Ecol Prog Ser 202:283-288

Worm B, Lotze HK, Sommer U (2001) Algal propagule banks modify competition, consumer and resource control on Baltic rocky shores. Oecologia 128:281-293

Submitted: September 29, 2017; Accepted: February 13, 2018 Proofs received from author(s): March 6, 2018 